\title{
Atuação dos professores de Atendimento Educacional Especializado junto aos estudantes com deficiência durante a pandemia do COVID-19
}

\author{
Performance of Specialized Educational Assistance teachers with students \\ with disabilities during the COVID-19 pandemic
}

Desempeño de los docentes de Asistencia Educativa Especializada con estudiantes con discapacidad durante la pandemia COVID-19

Fernanda Matrigani Mercado Gutierres de Queiroz

Professora doutora da Universidade Federal da Bahia, Salvador, BA, Brasil

E-mail: fernanda.queiroz@ufba.br ORCID: https://orcid.org/0000-0002-0724-7378

Márcia Helena da Silva Melo

Professora doutora da Universidade de São Paulo, São Paulo, SP, Brasil

E-mail: mmelo@usp.br ORCID: https://orcid.org/0000-0002-2061-1832

Recebido em 09 de fevereiro de 2021

Aprovado em 21 de junho de 2021

Publicado em 27 de julho de 2021

\section{RESUMO}

A educação inclusiva acolhe a diversidade no ambiente escolar e as ações do Professor do Atendimento Educacional Especializado (AEE) são importantes para a efetivação da inclusão dos estudantes público-alvo da Educação Especial, que são os que apresentam deficiências, transtornos globais do desenvolvimento ou Altas habilidades/superdotação. Em 2020, as escolas precisaram suspender as aulas presenciais devido à pandemia do COVID-19. Assim, propôs-se esta pesquisa com o objetivo de analisar a atuação dos professores do AEE junto aos estudantes com deficiência da Educação Básica durante o período de isolamento social imposto pela pandemia do COVID-19. Este estudo consiste numa pesquisa descritiva, quantitativa e qualitativa desenvolvida por meio da aplicação de questionário virtual junto aos Professores do AEE. Participaram 100 professores do AEE que atuavam na Educação Básica. Nos resultados e discussão deste estudo apresenta-se, primeiramente, o perfil dos professores de AEE participantes e na sequência sua atuação durante o período da pandemia junto aos estudantes e suas famílias, bem como sua atuação em relação às demandas escolares inerentes a função. Os professores demonstraram preocupação que os estudantes mantivessem uma rotina de estudos para sua aprendizagem, bem como, demonstram sensibilidade às dificuldades que muitas famílias enfrentam em relação à internet e equipamentos para as aulas on-line. Buscavam, então, alternativas viáveis em cada realidade para que isso não fosse mais um aspecto de exclusão, diante de tantos obstáculos já enfrentados pelas famílias neste período. Recomenda-se a ampliação de pesquisas com a participação do Professor do AEE em diferentes regiões do país.

Palavras-chave: Educação Inclusiva; Atendimento Educacional Especializado; Pandemia. 
http://dx.doi.org/10.5902/1984686X64174

\section{ABSTRACT}

Inclusive education welcomes diversity at school and the actions of the Teacher of Specialized Educational Assistance (SEA) are important for the effective inclusion of students targeting Special Education, who are those with disabilities, global development disorders or high skills / giftedness. In 2020, schools needed to suspend face-to-face classes due to the COVID-19 pandemic. This research was proposed with the objective of analyzing the performance of SEA teachers with students with disabilities in Basic Education during the period of social isolation imposed by the pandemic of COVID-19. This study consists of a descriptive, quantitative and qualitative research developed through the application of a virtual questionnaire with the Teachers of AEE. 100 teachers from SEA who worked in Basic Education participated. In the results and discussion of this study, the profile of participating SEA teachers is presented first and then their performance during the period of the pandemic with students and their families, as well as their performance in relation to school demands inherent to the function. Teachers showed concern that students maintained a study routine for their learning, as well as showing sensitivity to the difficulties that many families face in relation to the internet and equipment for online classes. They sought then, viable alternatives in each reality so that this was no longer an aspect of exclusion, in the face of so many obstacles already faced by families in this period. It is recommended to expand research with the participation of the ESA Professor in different regions this country.

Keywords: Inclusive education; Specialized Educational Assistance; Pandemic.

\section{RESUMEN}

La educación inclusiva abarca la diversidad en la escuela y las acciones del Profesor de Asistencia Educativa Especializada (AEE) son importantes para la inclusión de los estudiantes que se dirigen a la Educación Especial, que son aquellos con discapacidades, trastornos del desarrollo global o de altas habilidades / superdotación. En 2020, las escuelas debían suspender las clases presenciales debido a la pandemia de COVID-19. Esta investigación se propuso con el objetivo de analizar el desempeño de los docentes AEE con estudiantes con discapacidad en Educación Básica durante el período de aislamiento social impuesto por la pandemia de COVID-19. Este estudio consiste en una investigación descriptiva, cuantitativa y cualitativa desarrollada mediante la aplicación de un cuestionario virtual dirigido a Profesores de AEE. Participaron 100 docentes que trabajaban en Educación Básica. En los resultados y discusión de esta investigación se presenta primero el perfil de los docentes participantes y luego su desempeño durante el período de la pandemia con los estudiantes y sus familias, así como su desempeño en relación a las demandas escolares inherentes a la función. Los docentes mostraron preocupación de que los estudiantes mantengan una rutina de estudios para su aprendizaje, así como demuestren sensibilidad en relación a la dificultad que enfrentan muchas familias en relación a internet y equipamiento para clases online. Buscaron entonces, alternativas viables en cada realidad para que éste dejara de ser un aspecto de exclusión, ante tantos obstáculos ya enfrentados por las familias en este período. Se recomienda ampliar la investigación con la participación del profesor de la AEE en diferentes regiones del país.

Palabras clave: Educación Inclusiva; Asistencia Educativa Especializada; Pandemia. 
http://dx.doi.org/10.5902/1984686X64174

\section{Introdução}

De acordo com a perspectiva educacional inclusiva a escola deve rever seus paradigmas em prol de acolher toda a diversidade existente na comunidade escolar (STAINBACK, STAINBACK, 1999) e segundo a Legislação educacional, os estudantes público-alvo da Educação Especial (PAEE), que são os que apresentam deficiências, transtornos globais do desenvolvimento ou Altas habilidades/superdotação (BRASIL, 2011), têm direito ao Atendimento Educacional Especializado (AEE).

Dentre as atribuições do professor do AEE, estão a produção e organização dos serviços, recursos pedagógicos e de acessibilidade. Elaboração e execução do plano do AEE e dos atendimentos na sala de recursos multifuncionais. Estabelecimento de parcerias na elaboração de estratégias, na disponibilização de recursos de acessibilidade e pedagógicos. Orientação aos professores, estabelecendo articulação com os professores do ensino comum e famílias. Instruir quanto ao uso da tecnologia assistiva para promoção da participação nas atividades escolares pelos estudantes PAEE (BRASIL, 2009).

No Brasil, a partir de março de 2020, as escolas suspenderam suas aulas devido à situação da pandemia do COVID-19. Assim, estados e municípios organizaram seus decretos de acordo com orientação do Conselho Nacional de Educação (CNE) e muitas escolas passaram abruptamente a oferecer as aulas via plataformas on-line ou buscaram outros caminhos para atingir seus objetivos pedagógicos, sem impactar no isolamento social necessário para contenção da pandemia.

Segundo Oliveira e Leite (2007), o êxito da educação inclusiva dependerá da oferta de uma rede de apoio através de orientação, assessoria e acompanhamento à inclusão. Porém, este acompanhamento está sendo oferecido durante este período da pandemia? Quais as possibilidades encontradas pelas redes de ensino mediante o ensino remoto para atender os estudantes com deficiência? Como se estrutura o serviço do AEE? Há relacionamento e parceria colaborativa entre os profissionais do ensino comum, do AEE? Estas são algumas questões que justificam a necessidade desta pesquisa.

Estas questões devem ser discutidas no espaço educativo atual, bem como, no âmbito das pesquisas científicas, principalmente, tendo em vista que em torno de 74,9\% da população hoje, possui acesso à internet, segundo dados do Instituto Brasileiro de Geografia e Estatística - IBGE (BRASIL, 2018), percebe-se o potencial das redes virtuais para disseminação do conhecimento. 
http://dx.doi.org/10.5902/1984686X64174

Como mencionou Gadotti (2011), na atualidade as novas tecnologias possibilitaram novos espaços para aprendizagem, dentre eles o espaço domiciliar e a situação imposta pela pandemia veio acelerar este processo, porém, não podemos desconsiderar a importância do acesso ao ciberespaço para formação e aprendizagem sob o olhar da perspectiva educacional inclusiva que atenda a todos e a cada um, ou seja, há de se pensar como acolher toda a diversidade e possibilitar o acesso à internet de banda larga com qualidade, bem como equipamento de informática e Tecnologia Assistiva para os estudantes que precisarem.

A Resolução n 4/2009 recomenda que o professor do AEE desenvolva um trabalho educacional voltado ao estudante com deficiência, atuando de maneira integrada ao professor do ensino comum (BRASIL, 2009). Diante deste cenário se revela o objetivo desta pesquisa em analisar a atuação dos Professores do AEE junto aos estudantes com deficiência da Educação Básica durante o período de isolamento social imposto pela pandemia do COVID-19, na opinião desses professores.

\section{Método}

Trata-se de uma pesquisa descritiva, quantitativa e qualitativa desenvolvida por meio da aplicação de questionário virtual, contendo perguntas abertas e fechadas voltadas aos Professores do AEE que atuavam junto aos estudantes com deficiência nas escolas de Educação Básica brasileiras. Foi submetido ao Comitê de Ética em pesquisa com seres humanos e aprovado pelo CAAE: 34652520.0.0000.5531, parecer número: 4.153.712.

Participaram 100 professores do $\mathrm{AEE}^{1}$ que atuavam no atendimento ao estudante com deficiência em escolas da Educação Básica no Brasil. Os participantes, após lerem o Termo de Consentimento Livre e Esclarecido, aceitaram participar da pesquisa, expressando o aceite digitalmente. Preencheram um questionário virtual no qual relataram suas experiências profissionais referentes ao período de isolamento social decorrente da pandemia do COVID-19. Os critérios de inclusão foram: atuar na função de professor do AEE em escolas ou instituições que atendam estudantes com deficiência da Educação Básica. Possuir acesso à internet e aceitar participar da pesquisa. E os critérios de exclusão: profissionais que atuam em outras funções relacionadas às pessoas com deficiência. Não ter acesso à internet ou não aceitar participar.

O instrumento de coleta de dados foi o questionário on-line, contendo questões abertas e fechadas, na plataforma Google forms. Vieira (2009, p.15) define o questionário 
http://dx.doi.org/10.5902/1984686X64174

como um instrumento de pesquisa constituído por uma série de questões sobre determinado tema. A autora afirma que questionários bem elaborados trazem valiosas informações para a pesquisa, porém, há pessoas que hesitam em respondê-lo.

Para refinamento do delineamento metodológico e verificação da clareza das questões elaboradas foi realizada uma aplicação piloto dos questionários. Para responder, os participantes necessitaram de acesso à internet e equipamento como computador, notebook, tablet ou smartphone.

Os participantes receberam o link para acesso ao questionário via redes sociais, distribuídos em grupos de professores de conhecimento dos pesquisadores, que continham professores do AEE, com representatividade de todas as regiões do Brasil, como membros. $E$ fora solicitado que compartilhassem o questionário com outros professores da mesma categoria caracterizando-se por amostra de conveniência. Após leitura, concordância e assinatura digital do termo de consentimento livre e esclarecido. Cada participante teve acesso e respondeu ao questionário on-line, levando em média 15 minutos para respondê-lo. A distribuição do questionário se encerrou quando foi atingido o número de participantes, tendo ficado disponível de 15 de julho a 15 de agosto de 2020.

\section{Resultados e Discussão}

Primeiramente, serão apresentados, o perfil dos professores de AEE participantes e na sequência sua atuação durante o período da pandemia junto aos estudantes e suas famílias, bem como, sua atuação em relação a demandas escolares inerentes a função.

\section{Perfil dos professores do AEE}

Os participantes são $94 \%$ professoras e $6 \%$ professores com a seguinte distribuição de faixa etária: $1 \%$ entre 18 e 27 anos, $15 \%$ de 28 a 37 anos, $49 \%$ de 38 a 47 anos, $27 \%$ de 48 a 57 anos e $8 \%$ com mais de 57 anos. Os respondentes atuavam nos seguintes estados do Brasil, 54\% em São Paulo, 30\% no Amazonas, 7\% na Bahia, 7\% no Ceará, $1 \%$ no Maranhão e 1\% em Minas Gerais, distribuídos por diversos municípios. Todos os questionários foram analisados e dentre os respondidos não houve representação dos demais estados. O Gráfico 1 demonstra o tempo de exercício profissional na função de professor do AEE. 
http://dx.doi.org/10.5902/1984686X64174

Gráfico 1: Tempo de exercício profissional na função de professor do AEE (n=100)

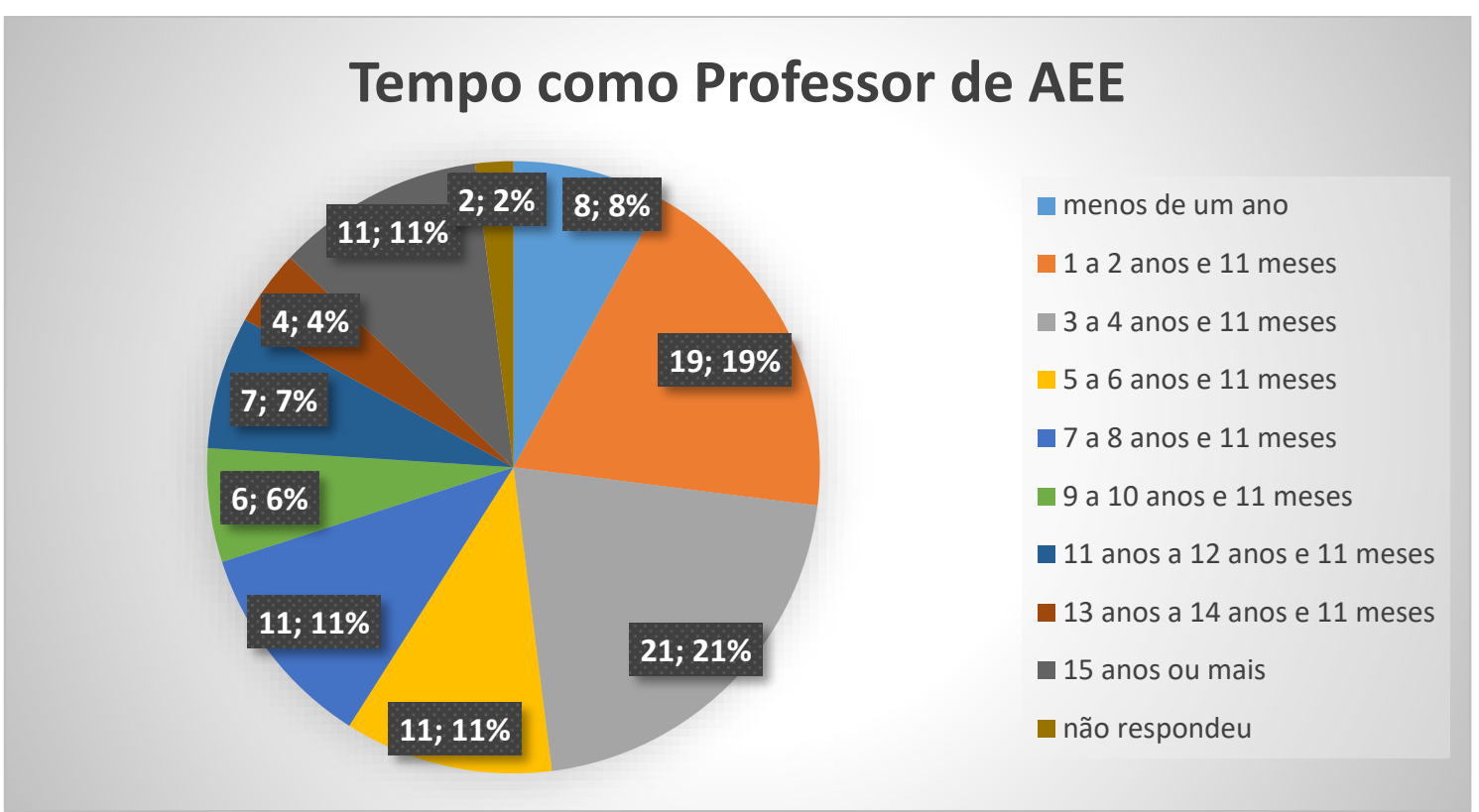

Fonte: Elaboração própria (2021).

Em relação à titulação, 50\% dos participantes referiram possuir especialização na área de Educação Especial ou em alguma de suas especificidades, como Deficiência Intelectual ou Transtorno do Espectro Autista (TEA), 28\% dos professores possuem especialização (em Psicopedagogia, Gestão Escolar, entre outras), 14\% graduação (em Pedagogia, Letras, Matemática, etc.), 6\% Mestrado (em Educação Especial, Matemática, etc.), e $2 \%$ o ensino médio.

A Resolução no 4/2009 especifica em seu Art.12 que para atuar no AEE, o professor deve ter formação inicial que o habilite para o exercício da docência e formação específica para a Educação Especial e a Resolução no 1/2007, que estabelece normas para 0 funcionamento de cursos de pós-graduação lato sensu, em nível de especialização, há a exigência de, pelo menos 360 horas na carga horária, sobre este aspecto. Carmo et al. comentam:

percebe-se que as políticas públicas educacionais de inclusão e de formação de professores, ao longo das últimas décadas, convergiram no sentido de assumir o paradigma da inclusão como norte para os sistemas de ensino no Brasil. Contudo, parece haver um descompasso entre as ações governamentais para a inclusão de alunos público-alvo da Educação Especial e a formação de professores para atendê-los, ficando esta última como uma preocupação secundária nas políticas públicas para a inclusão escolar (2020, p.2).

De acordo com os dados e as colocações dos autores, nota-se que ainda há dificuldades relacionadas a suprir a demanda por formação, em todo o território nacional, 
denotando um escasso fomento de políticas públicas para a formação do professor que atua no AEE.

O regime de trabalho expresso foram $72 \%$ efetivos, com ingresso via concurso público, 16\% referiram contrato temporário, $11 \%$ CLT, e 1\% não responderam. A maioria atua como professor de AEE na Rede Pública Municipal 70\%, 24\% na Rede Estadual de Ensino e 2\% em Instituições, como, por exemplo, a APAE, AMA, entre outras e 4\% em mais de uma Rede de Ensino. Nenhum participante mencionou atuar em Escola Particular ou Rede Pública de Ensino Federal. O Gráfico 2 se refere ao local de atuação desses professores:

Gráfico 2: Local de atuação dos professores $(n=100)$

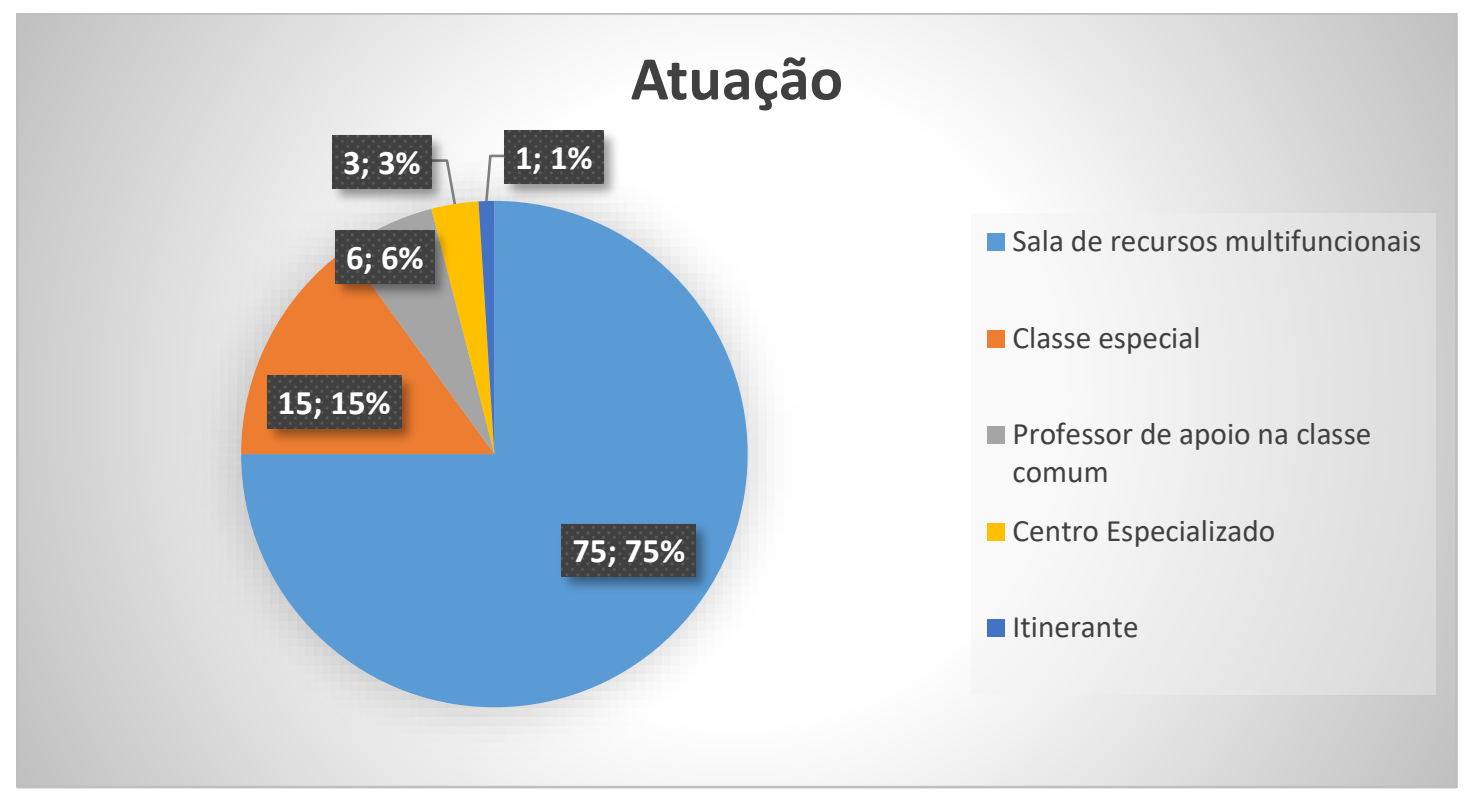

Fonte: Elaboração própria (2021).

Esta distribuição demonstra conformidade com a legislação educacional, com a maioria dos professores do AEE atuando em Salas de Recursos Multifuncionais. Porém, cabe destacar o número ainda expressivo de classes especiais revelando a necessidade de aumentar o fomento às ações inclusivas, como, por exemplo, a implementação de sala de recursos e pesquisas na perspectiva educacional inclusiva.

Quanto aos níveis de ensino dos estudantes acompanhados pelos professores, 79,8\%, eram de estudantes do Ensino Fundamental I (10 ao 5o ano), 52,5\% eram do Ensino Fundamental II (6ํㅜㅇ ao $9^{\circ}$ ano), 33,3\% da Educação Infantil, 12,1\% do Ensino Médio e 1\% não respondeu. A maioria dos participantes atendia estudantes de mais de um nível de ensino, na ocasião da pesquisa. 
http://dx.doi.org/10.5902/1984686X64174

Os participantes atendiam estudantes que apresentavam Deficiência Intelectual (27,25\%), na sequência o Autismo (24,35\%), Deficiência múltipla (12,75\%), Deficiência física que não usa cadeira de rodas (10,43\%), Deficiência física usuário de cadeira de rodas $(9,86 \%)$, Baixa visão $(8,12 \%)$, Surdez $(3,48 \%)$, Cegueira $(2,61 \%)$, Outros $(0,87 \%)$ e Microcefalia (0,29\%). Também relataram que acompanhavam diversos estudantes, portanto indicaram mais de uma deficiência.

Esta caracterização demonstrou o perfil dos professores dos AEE participantes e o seu contexto de trabalho. Considerando que muitas escolas da educação básica no Brasil, tiveram que adotar repentinamente outras formas de atenderem seus estudantes, a segunda categoria de análise desta pesquisa se configura pela atuação dos professores de AEE junto aos estudantes e suas famílias.

\section{Atuação dos professores do AEE junto aos estudantes e suas famílias}

Dentre os participantes, 94\% continuaram mantendo contato com os estudantes e suas famílias durante o período de isolamento físico imposto pela pandemia, somente 6\% não mantiveram contato. Esta interação não presencial se caracterizou majoritariamente pelo WhatsApp, seja por ligações, vídeochamadas ou formação de grupos no aplicativo, como se pode perceber no Gráfico 3.

Gráfico 3: Formas de contato com os estudantes e suas famílias ( $n=94)$

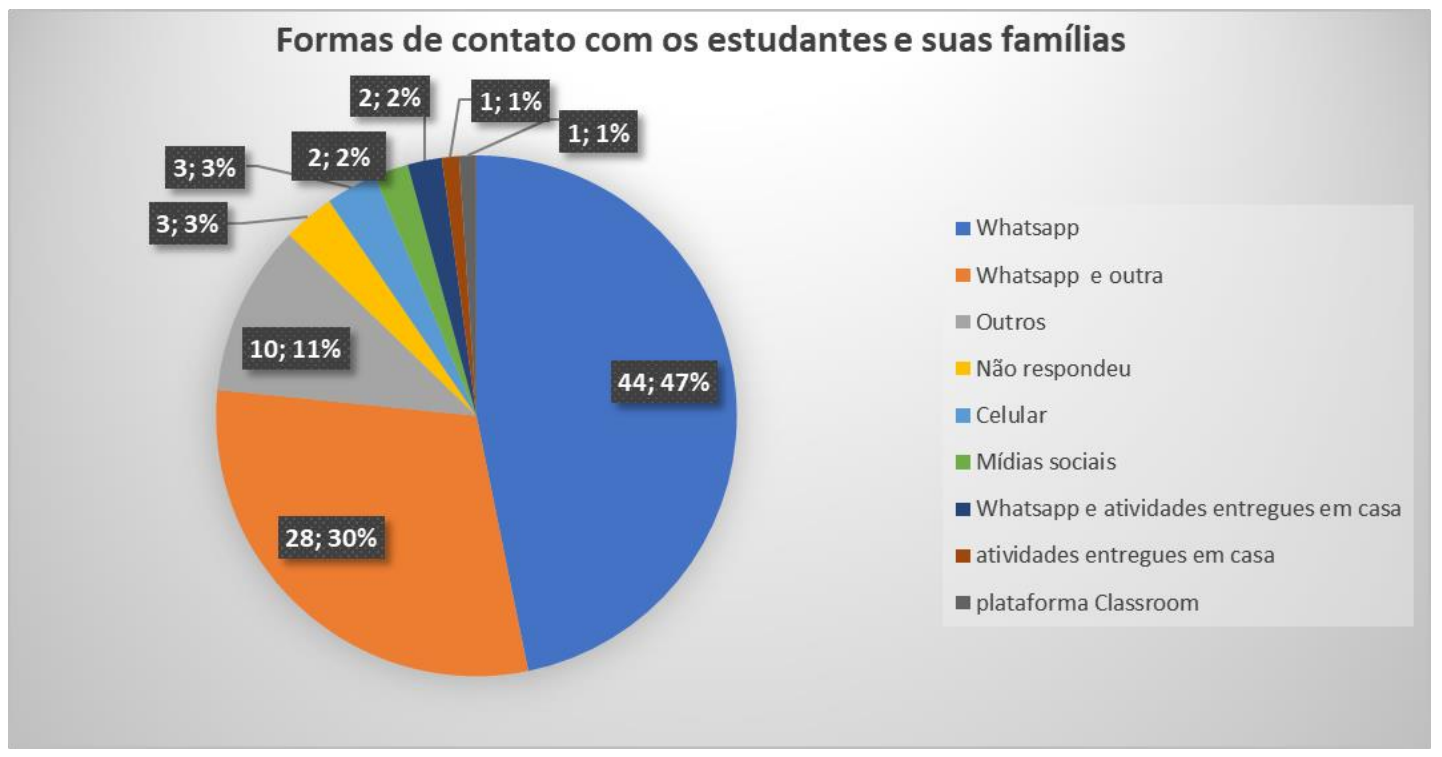

Fonte: Elaboração própria (2021).

Uma porcentagem expressiva $(44,4 \%)$ associou o contato pelo WhatsApp a outra plataforma on-line (como o Meet, Google Classroom, Zoom, , bem como telefonemas e e- 
http://dx.doi.org/10.5902/1984686X64174

mails). Em menor número, apontaram: WhatsApp mais atividades entregues em casa. Ou respostas mais genéricas como uso do celular, sem especificar se foram ligações, vídeochamadas etc.

Os participantes que se referiram à qualidade do contato o expressaram como bom, proveitoso e muito produtivo. No entanto, P 37 informou: "[...] poucos pais me dão retorno das atividades enviadas". Assim, os professores demonstraram a preocupação que os estudantes mantivessem uma rotina de aprendizagem.

A frequência desses contatos foram semanalmente (45\%), duas ou mais vezes por semana (44\%), esporadicamente, sem data certa (8\%) e quinzenalmente (3\%). Os dados revelam a predisposição dos professores à manutenção do vínculo com os estudantes, embora tenham encontrado adversidades nesse percurso, procuraram verificar qual o meio mais acessível às famílias, em acordo com o Parecer $n^{0} 5$ do Conselho Nacional de Educação (BRASIL, 2020).

A análise de conteúdo dos assuntos abordados nas conversas entre o professor de AEE com o estudante PAEE e/ou sua família revelou duas categorias temáticas Atividades escolares e Assuntos relacionados à saúde, que se desdobraram em subcategorias discutidas a seguir.

A primeira categoria se refere às Atividades escolares, da qual emergiram as seguintes subcategorias: Aprendizagem, na qual os professores relataram os meios pelos quais acompanharam a aprendizagem dos estudantes e a preocupação que eles mantivessem uma rotina de estudos, como pode ser percebido nas colocações de P72: "Conversamos sobre o desenvolvimento da criança, sobre as atividades e algumas vezes eles compartilham suas dificuldades sobre a deficiência da criança nesse momento de pandemia". Ou, P 70: "acompanhamento dos conteúdos enviados pelo professor do ensino regular e adaptação dos conteúdos".

A subcategoria Procedimentos para o ensino remoto e orientações aos pais, na qual os professores relatam como procederam frente a orientações aos estudantes e suas famílias sobre o uso de ferramentas digitais para o ensino remoto, bem como em relação ao procedimento para realização das atividades propostas, como expressou P75: "Dúvidas sobre as atividades, quaisquer outros assuntos que as famílias tenham dúvidas e as dificuldades de acesso à internet". Em relação a isso, o documento Protocolos sobre Educação Inclusiva durante a pandemia da COVID-19 orienta que o vínculo entre escola e 
http://dx.doi.org/10.5902/1984686X64174

famílias deve ser mantido para um acompanhamento próximo do desenvolvimento dos alunos.

\begin{abstract}
Educadores, professores do Atendimento Educacional Especializado e gestores escolares precisam continuar a trabalhar juntos para promover uma educação inclusiva, especialmente quando são adotados modelos de ensino a distância. Todos os materiais de aula e de apoio devem ser acessíveis aos estudantes com deficiência e pensados segundo suas especificidades. A construção de um ensino online inclusivo pode ser uma grande oportunidade de reconstrução das maneiras de ensinar e aprender (INSTITUTO RODRIGO MENDES, 2020, p. 48).
\end{abstract}

Na subcategoria Questões dos estudantes relacionadas à deficiência, os participantes expressaram sobre acessibilidade, adaptações de atividades e questões comportamentais dos estudantes, bem como expressaram dificuldades encontradas como a seguinte argumentação de P53:

Dificuldades para desenvolver o trabalho como: falta de material lúdico, falta de conhecimento dos responsáveis, orientações escritas ou faladas não são suficientes porque nós, na sala, dispomos de ferramentas que nos ajudam a realizar as tarefas. Então, buscamos utilizar o que eles dispõem em casa. Alguns já compraram jogos pedagógicos para facilitar o trabalho. Eu vou dando dica do que eles podem usar para efetuar as tarefas. O importante é que estamos caminhando.

Assim, os participantes relataram como tem sido o acompanhamento junto aos estudantes PAEE expressando sobre assuntos referentes ao desenvolvimento dos estudantes e problemas relacionados às práticas pedagógicas e de acessibilidade aos conteúdos e materiais. Segundo Telles et al. (2020), refletir sobre as condições de acessibilidade requer a compreensão da singularidade de cada discente e do contexto, para, dessa forma, construir uma educação verdadeiramente inclusiva. Se a acessibilidade é um desafio a ser enfrentado no ensino presencial não é diferente no ensino remoto. Tornase mais uma barreira a ser enfrentada pela comunidade escolar, dado que as condições de acessibilidade com os estudantes em casa ficaram bastante restritas, sem os recursos de Tecnologia Assistiva e pedagógicos das Salas de Recursos multifuncionais.

$\mathrm{Na}$ categoria Assuntos relacionados à saúde, os participantes relataram acerca dos agravos a saúde física e mental informados pelas famílias, como $P$ 72: "[...] algumas dificuldades familiares, alguns pais foram contaminados pela COVID e tiveram que se ausentar da família, ficar confinados e a perda de alguns familiares por conta do vírus". Ou P 49, "conversamos a respeito da saúde da criança que acompanho, atividades e vídeos de apoio que recomendo. Continuamente dou palavras de incentivo." 
http://dx.doi.org/10.5902/1984686X64174

Os professores que alegaram não manter contato indicaram como motivos: P63 "Infelizmente não deu tempo de conhecer todos os alunos e ter o contato atualizado deles[...] nem todos fizeram contato com a escola. Muitos não têm as tecnologias disponíveis e as dificuldades são diversas." Ou, o relato de P93 que voltou de licença maternidade durante a pandemia e expressa: "o contato com as famílias via plataforma Google utilizada pelo município, no meu caso, não tenho retorno dos alunos e familiares."

Neste período de isolamento físico decorrente da pandemia, 37\% dos participantes relataram conseguir realizar atividades pedagógicas com todos os estudantes com deficiência, 53\% com alguns, 4\% não estão conseguindo realizar as atividades e 6\% não responderam. Dentre os que estão conseguindo realizar as atividades, a maioria mencionou o uso de ferramentas digitais e somente quatro professores a realização de atividades impressas, seja enviada pela escola ou impressa pelos pais. As atividades versavam acerca das temáticas: atividades teóricas e práticas, de leitura, escrita e alfabetização. Atividades da apostila, lúdicas e de contação de histórias, bem como, direcionadas as especificidades dos estudantes. Atividades sobre a COVID-19, higienização preventiva para estudantes e seus familiares, através do celular. Aulas interativas pelo Youtube para trabalhar conteúdos matemáticos, jogos, histórias, música de movimento, entre outros, construindo com materiais recicláveis que os pais têm em casa, foi mencionado também, revisão sobre frutas, animais e outros temas, dependendo muito da idade e ano escolar do perfil do estudante atendido. Assim, P100 comentou:

Cada aluno está em uma etapa de aprendizagem. Então, as atividades são preparadas diferentemente para cada um deles. Encaminho atividades desde coordenação motora, alfabetização, até leitura e interpretação. Noção de lateralidade à resolução de situações problema. Com alguns alunos, consigo perceber avanço na aprendizagem. Com outros não há avanço. Depende muito de cada família.

De acordo com os relatos, percebe-se que, independentemente da forma das atividades, seja impressa ou on-line, há necessidade de participação da família na realização das atividades, embora, não forneçam detalhes de como se espera que seja esta participação ou se foi dada alguma orientação nesse sentido. Acerca desta dificuldade de participação familiar, Ferreira e Barbosa (2020, p. 14) argumentam que "quando a questão não é o acesso, outros fatores também incidem sobre a organização do ambiente doméstico e geram preocupações". As autoras enumeram os cuidados com o lar realizados pelas crianças e adolescentes enquanto os adultos necessitam trabalhar, violência doméstica, diminuição da renda, adoecimento, entre outros fatores. Neste sentido, P99 relatou: 
http://dx.doi.org/10.5902/1984686X64174

No início da quarentena, as famílias pareciam mais engajadas no auxílio da execução das atividades, uma vez que os alunos são dependentes de orientação. Em alguns casos, é necessário fazer o contato no início da semana e estimular a execução, algumas vezes funciona, outras, mesmo com insistência, não tive retorno.

Ainda sobre as atividades realizadas, dois participantes mencionaram o trabalho colaborativo com o professor do ensino comum para planejamento e realização. Por sua vez, os professores que informaram não conseguir realizar atividades alegaram como motivo que as famílias não demostraram interesse em receber atividades pelo WhatsApp, não conseguiram acessar devido à falta de internet ou celular.

Sobre o modo como os estudantes atendidos acessavam as atividades escolares neste período de isolamento, os participantes puderam mencionar mais de uma opção, conforme os atendimentos que estavam acontecendo. A maioria afirmou que a família estava fazendo a mediação pelo celular (33\%), o estudante ou sua família buscavam o material didáticopedagógico na escola $(23,5 \%)$, interação se dava diretamente com o estudante pelo celular (20\%), a família do estudante fazia a mediação pelo computador, como: ligar o equipamento, ajustar configurações ou softwares de acessibilidade, detalhar a atividade, atuar como leitor para o estudante, entre outras $(9,5 \%)$, a rede de ensino/escola enviou o material pelo correio (5\%), a relação ensino-aprendizagem ocorreu diretamente com o estudante pelo computador (5\%) e outras formas (4\%), como: aula pela TV, a professora entregou pessoalmente nas residências dos alunos ou entregue por mensageiros. A diversidade de formas de atendimento relatadas anuncia que os professores do AEE demonstraram preocupação com as necessidades educacionais deste público e desta maneira procuraram tornar o ensino acessível aos estudantes PAEE, na medida do possível.

Em relação ao professor acreditar que diante dessas medidas as necessidades educacionais destes estudantes estavam sendo atendidas durante este período de isolamento físico, $71 \%$ responderam que parcialmente, cujos motivos alegados foram: P14 "A mediação professor-aluno requer presença física, mesmo com as redes sociais fica um pouco difícil obter um maior aproveitamento", ou P12: "mesmo a família sendo parceira e ajudando em todo o processo, não se compara as estimulações em sala de aula." P25 relatou:

Os responsáveis tentam fazer o possível, mas, a descontinuidade diária escolar, é um grande prejuízo nessa fase do desenvolvimento. Ainda mais para o nosso público que não conta com outros estímulos. As atividades são lúdicas, adaptadas, no entanto muitos pais fazem pela criança por não saber mediar. Todas as atividades são filmadas ou fotografadas para que eu possa dar um feedback. 
http://dx.doi.org/10.5902/1984686X64174

Nessa direção também há outros argumentos, como P36: "nem todos estão sendo atendidos, há dificuldade da família em acompanhar e a parte lúdica se perdeu um pouco pela ausência de materiais". Ou P69, "[...] a convivência, a troca de experiências com os colegas e professores é fundamental para o desenvolvimento da aprendizagem. Nada substitui o contato humano, o olho no olho". Foi mencionado por P63: "Porque tem aqueles que têm tecnologia e apoio da família, mas, muitos lugares que assistiam aos nossos alunos na área da saúde deixaram de atender."

Em continuidade, 16\% acreditam que as necessidades educacionais destes estudantes estão sendo atendidas, como argumenta P31: "Os pais nos passam o que cada um está desenvolvendo, eles nos dão retorno pelo WhatsApp" ou P47: "Os alunos, com o auxílio do professor, através do celular ou computador e a ajuda dos pais, têm respondido as atividades enviadas e são feitas sondagens para aferir o aprendizado". P54 expressou: "porque nas evidências enviadas pelas crianças de volta para nós, as atividades são feitas com êxito" e P50: "sim, porque temos criado grupos de estudos, levado material impresso, criado vídeos e tutoriais dando orientações".

Por outro lado, 13\% acreditam que não, e os motivos alegados para escolha da resposta foram, P33: "Mesmo com adaptações nas atividades enviadas por WhatsApp, os pais, em sua maioria, têm problemas de internet e dificuldades em ajudar as crianças em questões pedagógicas". Coaduna a resposta de P16: "sem a mediação adequada, as adaptações sugeridas, não são tão eficientes para a aprendizagem dos estudantes e nem sempre a família consegue realizar esta mediação".

P13 expressou a "falta compromisso da família", e P18 argumentou que "[...] infelizmente, alguns pais não conseguem ensinar as tarefas propostas, às vezes, por falta de tempo ou mesmo estando em casa não priorizam este trabalho com os filhos”. Ou P21: "as mães reclamam o quão difícil é estar no lugar do professor, ensinando matérias que nem elas sabem". Também foi mencionado por P19 que: "A ausência do contato pessoal com a professora e seus pares, interfere significativamente no processo de ensinoaprendizagem." Neste sentido, P29 argumentou:

Há situações em que o mais importante é o contato presencial, a observação in locus e o manejo direto com as dificuldades apresentadas. Porque os pais/responsáveis não tem formação e conhecimento na área psicopedagógica para atender as necessidades dos alunos, além de não ter a sala de recursos multifuncionais e os meios adequados para o atendimento. 
Foi mencionada a situação de estudantes com deficiência que têm pais idosos, que apresentam dificuldades com a tecnologia e outros que residem em abrigos. Nota-se que os principais pontos abordados que dificultaram a mediação pedagógica foram: a falta de internet e equipamentos adequados, despreparo dos pais e dificuldade na interação com o professor e colegas. Neste sentido, Queiroz expressa que "embora os recursos tecnológicos auxiliem o trabalho do professor, o mais importante está na mediação pedagógica realizada [...] a diferença está na atuação do professor por meio das estratégias planejadas" (2015, p. 85).

Diante do contexto pandêmico, foi questionado se os professores do $A A E$ conseguiram passar alguma orientação para os estudantes ou suas famílias sobre as questões de saúde referentes à pandemia, conforme expresso no Gráfico 4.

Gráfico 4: Orientação para os estudantes ou suas famílias sobre as questões de saúde ( $n=100)$

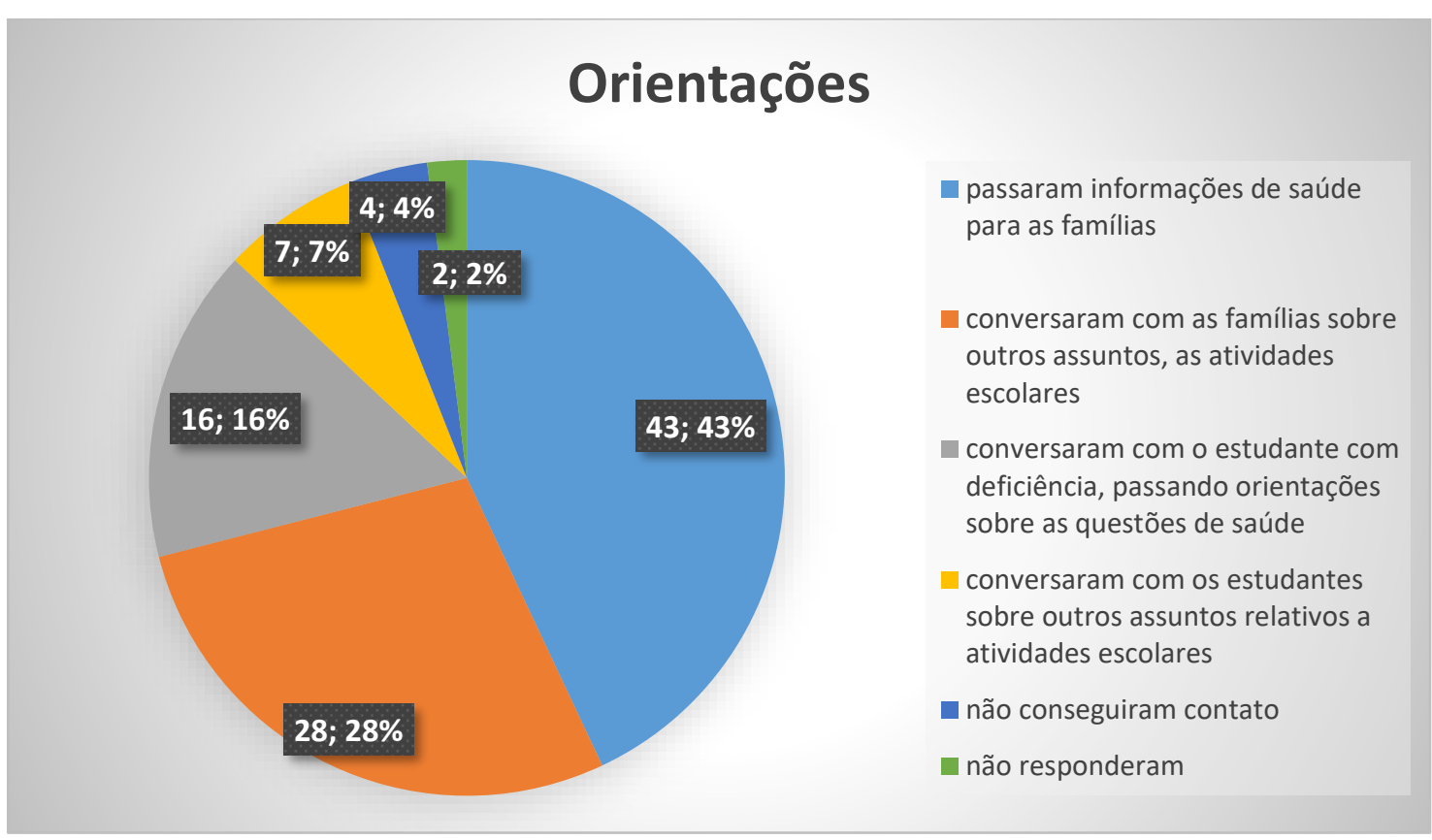

Fonte: Elaboração própria (2021).

Os professores que transmitiram informações de saúde para os estudantes ou suas famílias referiram abordar sobre: profilaxia, higiene e saúde para o estudante e sua família, atividades relacionadas à prevenção e cuidados, intensificar a lavagem das mãos, ficar em casa e se precisarem sair, usarem máscara, uso do álcool em gel e manter o distanciamento social. Indicação de lives sobre o assunto da pandemia, bem como vídeos e links relacionados a atividades práticas de higiene, de acordo com as orientações da 
http://dx.doi.org/10.5902/1984686X64174

Organização Mundial de Saúde (OMS), disponibilização de cartilha digital sobre o assunto. Todas as informações dadas foram discutidas com os coordenadores pedagógicos.

Os participantes que informaram conversarem sobre assuntos relativos às atividades escolares com os estudantes ou suas famílias abordaram: notícias, mensagens oficiais focadas nas necessidades do dia a dia, manter a rotina de estudos, dentro do possível, atividades sobre Língua Brasileira de Sinais (LIBRAS), trabalho com as emoções a partir de uma história, atividades para desenvolver a autonomia, uso de recursos pedagógicos, também foi mencionada a atitude familiar de realizar junto às crianças atividades motoras lúdicas de fácil realização como músicas com gestos e trabalho com a apostila.

Sobre a disponibilização de material aos estudantes pela rede de ensino, seja impresso ou virtual, $83 \%$ informaram que a rede disponibilizou material e 17\% não. Dentre os materiais disponibilizados $51,2 \%$ possuía acessibilidade, $27,9 \%$ não e $20,9 \%$ parcialmente. Neste sentido $60,8 \%$ dos professores comentaram ter que adaptar o material didático pedagógico para os estudantes com deficiência, ou seja, alguns materiais estavam acessíveis e outros não, ou, possuíam algum recurso de acessibilidade como legenda ou interpretação de LIBRAS, mas, não possuíam descrição ou vice-versa, bem como a adaptação de texto para o estudante com deficiência intelectual, que, por vezes, precisa ser mais individualizada, de acordo com suas características de aprendizagem.

De acordo com o expresso pelos professores, as adaptações realizadas foram: transformar o texto para letra bastão, adequação de linguagem, acréscimo de figuras ou marcação de palavras-chave, para auxiliar a compreensão de texto enviado ao estudante. Foi mencionado, também, a interpretação em LIBRAS, realizar jogos a partir de textos propostos, contação de histórias, fonte ampliada de acordo com a necessidade do estudante, apoio de Comunicação Suplementar e Alternativa, jogos lúdicos no celular, situações problemas ilustradas, frações com recursos que a família tenha em casa, por exemplo, cortar uma maçã na metade, $1 / 4$, e assim por diante.

A maioria relatou resultados positivos na aprendizagem dos estudantes após a adaptação realizada nas atividades, alguns participantes alegam que continua muito difícil. P77 relatou a elaboração e envio aos pais de um tutorial de como realizar as adaptações das atividades para os filhos e outras orientações de como atuarem como escribas e ledores. P92 mencionou ter enviado áudio à família explicando o direcionamento de atividades. 
http://dx.doi.org/10.5902/1984686X64174

Referente à adaptação de materiais para os estudantes com deficiência 8,2\% informaram que o material não estava acessível e não foi possível adaptá-lo. Dentre os professores que comentaram ter que adaptar o material didático pedagógico para os estudantes em $68 \%$ dos casos o professor do AEE que realizou esta adaptação, $26 \%$ a adaptação foi realizada em parceria com o professor do ensino comum, 1\% relatou que a adaptação foi realizada exclusivamente pelo professor do ensino comum, 9\% foi realizada pela família, $1 \%$ relato de adaptação feita pelo coordenador pedagógico e 1\% pela equipe de educação especial do município. Nas demais situações, ou não houve material ou este não foi adaptado. Eles puderam responder mais de uma alternativa nesta questão.

Sobre o Uso de Tecnologia Assistiva pelos estudantes atendidos, 52\% responderam que não utilizam, 47\% utilizam e 1\% não respondeu. Dentre os que utilizam os recursos indicados foram: Comunicação Suplementar e Alternativa, lupa, lente de aumento e software leitor de texto, máquina braille, lápis adaptado/engrossado e tesoura adaptada, plano inclinado, áudio book e livro ampliado, recursos para acesso ao computador e mobiliário que atenda às necessidades posturais do estudante. Alguns participantes deram respostas muito vagas, como, por exemplo, celular, não sendo possível identificar se fazia referência a algum aplicativo de acessibilidade no aparelho. Outros revelaram desconhecimento sobre Tecnologia Assistiva, confundindo-a com o uso das plataformas de ensino remoto, vídeoaula ou terapias: como a terapia ocupacional ou a fisioterapia. Estes dados corroboram com o estudo de Pagaime et. al (2020), que colocam a falta de recurso de tecnologia assistiva como uma das principais barreiras enfrentadas pelos estudantes.

Em relação aos softwares ou aplicativos que utilizam na prática de ensino junto aos estudantes com deficiência atendidos no período, os professores responderam: 95\% WhatsApp, 48\% YouTube, 42\% Google Meet, 33\% Google Sala de aula, 22\% Facebook, 18\% Zoom, 11\% Microsoft Teams, 6\% Hangouts, 5\% Telegram, 4\% Skype, 4\% Stream Yard, 4\% mencionaramou que não estão atendendo nenhum aluno, 1\% que utilizam o Moodle e $3 \%$ outras respostas, como, por exemplo, respostas vagas como: o software mais acessível para eles, mas, sem especificar. Percebe-se pelo quantitativo de softwares respondidos que os professores associam mais de uma ferramenta digital ao sistematizar sua prática pedagógica.

Somente 59\% afirmaram que os softwares indicados apoiavam adequadamente sua prática pedagógica, 37\% responderam que apoiavam parcialmente, $1 \%$ que não apoiavam e $3 \%$ não responderamu. Dentre os que mencionaram que o software atendia sua 
http://dx.doi.org/10.5902/1984686X64174

necessidade, justificaram que com eles conseguiam realizar as atividades, obtinham 0 melhor resultado com o aluno, foram os mais acessíveis e fáceis de usar porque eram os que os pais tinham instalados no celular. Assim, o acesso é fácil e ágil para o aluno, permite gravação de videoaulas, o envio de materiais com acessibilidade e suporte ao estudante. Também mencionaram que as ferramentas do Google permitem o alcance de objetivos específicos voltados às dificuldades individuais dos alunos.

Por esses motivos os professores necessitam variar o tipo de software utilizado, de acordo com o perfil do estudante, disponibilidade do software e/ou conteúdo a ser trabalhado. Mencionaram também, que nem todos têm acesso à internet e a acessibilidade das ferramentas digitais ainda se mostra insuficiente, há oscilação na internet e casos em que há necessidade de mediação de um membro da família. Neste sentido, Menezes afirma que:

\begin{abstract}
$\mathrm{Na}$ era da cibercultura estamos conectados em maior ou menor grau através das tecnologias de informação e comunicação em rede, mas o acesso às tecnologias informacionais não é homogêneo para as diversas regiões do globo, assim como não o é para todas as pessoas. A dispersão territorial, o alto custo da conexão e a baixa qualidade do sinal em regiões afastadas dos grandes centros não permitem usos efetivos e consistentes do potencial de criação das tecnologias em rede (2018, p. 27).
\end{abstract}

Mesmo assim, segundo as colocações dos professores, 67\% das famílias estão apoiando a forma do ensino adotado, 14\% estão reclamando; $9 \%$ das famílias por um lado apoiam e por outro rejeitam, alegando que estão fazendo o trabalho do professor ou preferem o ensino presencial; $5 \%$ estão confusas, não reclamam, mas, também não aderiram ao ensino remoto. Há $2 \%$ de famílias neutras, que não expressaram sua opinião para os professores e 3\% não estão gostando, mas, entendem que é o mais seguro para o momento.

Neste contexto, mencionaram que há famílias com dificuldades em organizar os horários de estudo dos seus filhos, outras que dividem um celular entre vários membros ou com dificuldades em relação ao uso da tecnologia. Alegam não ter tempo e conhecimento para apoiar o estudante ou falta de paciência para mediar a ação pedagógica. Por outro lado, há famílias engajadas, realizando as atividades e enviando os registros por fotos, fazendo perguntas aos professores e disseram que seus filhos estão evoluindo. Alguns compreendem que neste momento a participação familiar é primordial para o desenvolvimento da criança, oferecem suporte, conscientes de que não é o ideal, mas, o possível para o momento, pensando na segurança de todos. 
http://dx.doi.org/10.5902/1984686X64174

\section{Atuação em relação a demandas escolares inerentes a função}

De acordo com a Resolução $\mathrm{n}^{0} 4 / 2009$, o professor do AEE tem uma série de atribuições além do atendimento ao estudante PAEE, dentre elas: orientar os professores e o estabelecimento de parcerias para disponibilizar recursos de acessibilidade e elaborar estratégias de atendimento (BRASIL, 2009).

Neste período de isolamento físico decorrente da pandemia, a maioria, 95\% dos professores informaram manter contato com os colegas de trabalho e 5\% não. Os assuntos sobre os quais conversavam são: planejamento das aulas em reuniões de equipe, sobre a escola, atividades pedagógicas, didática, reflexões sobre textos estudados e estratégias de ensino, compartilhamento de fotos, atividades e troca de experiências, frequência/participação dos estudantes, como proporcionar a interação entre as atividades a serem executadas, uso de ferramentas digitais como o WhatsApp, Teams, Zoom e o Meet, condições de acesso e apoio da família para a execução das atividades. Haja vista que alguns não têm acesso à internet, como organizar para que atividades impressas cheguem aos alunos, volta às aulas. Declararam conversar também sobre o comportamento dos alunos, suas famílias e os desafios enfrentados na pandemia, assuntos relacionados à rotina nesse momento, as angústias do confinamento, saudades e outros assuntos.

Uma das temáticas abordadas pelos professores decorre de terem recebido algum suporte institucional para manter o contato pedagógico com os estudantes à distância $53 \%$ dos professores relataram ter recebido formação, 22\% alegaram não ter recebido nenhum suporte, seja formativo ou material, $21 \%$ disseram ter recebido materiais e/ou equipamentos, $8 \%$ informaram ter recebido somente o contato dos alunos e orientações, $2 \%$ disseram que estão se auxiliando mutuamente e $2 \%$ mencionaram ter recebido da Secretaria de Educação ou coordenação, mas, não esclareceram se foi material ou formação.

Sobre conseguir planejar as atividades em parceria com outros professores, $76 \%$ responderam que sim e as atividades mencionadas foram: adaptações das atividades propostas, que são inseridas na plataforma digital, de forma que os estudantes consigam realizá-las. Relatório e planejamento, adaptação do material e estratégias. Planejamento de atividades lúdicas, de vida diária, viso-motoras, de alfabetização, raciocínio lógico e de concentração, troca de experiências e flexibilização do material enviado pela prefeitura ou livros, jogos adaptados para o ensino de português e matemática. 
http://dx.doi.org/10.5902/1984686X64174

Houve o relato de divisão em grupos responsáveis em elaborar e planejar atividades para alimentar o drive, das atividades a serem postadas na plataforma para os estudantes realizarem. Estes grupos eram alterados periodicamente e subdivididos em áreas voltadas a deficiência visual, auditiva, TEA, percepção e memória, entre outras. P63 mencionou: "eu oriento os professores que me procuram, se possuem alguma dúvida, dou alguma dica".

Dentre os participantes $24 \%$ não estão conseguindo planejar as atividades em parceria com outros professores e mencionaram que: cada caso é específico, dificuldade de contato com os outros professores devido a organização da jornada de trabalho, não haver professor que trabalhe com a mesma deficiência ou os alunos estão no contraturno. P86 relatou: "os professores do ensino comum não me procuram". E P53: "o tempo é tão corrido que eu não pensei nisso". P89 mencionou: "a maioria dos professores não querem fazer as adaptações e até porque estes alunos são esquecidos". E P34 informou "não achar necessário".

Miranda (2015) ao pesquisar a articulação entre o AEE e o ensino comum para a construção de sistemas educacionais inclusivos ressalta a importância da colaboração entre o professor do AEE e do ensino comum, relatando benefícios para os estudantes quando isso ocorre. O estudo expõe também dificuldades como a incompatibilidade de horário entre os professores, o número elevado de alunos para serem atendidos no AEE, inadequada formação e pouca inserção no projeto político pedagógico da escola.

Em relação a participar de formação profissional nesse período, a maioria 57\% responderam que sim, oferecida pela própria instituição de trabalho, 35\% também respondeu que sim, porém, por iniciativa e custos próprios e $8 \%$ responderam que não. A maioria $86 \%$ gostaram da formação realizada, $6 \%$ não gostaram e $8 \%$ não responderam. As temáticas mencionadas pelos participantes foram: Uso de ferramentas tecnológicas, produção de filmes e jogos, cursos sobre o acolhimento aos familiares e estudantes, adaptações curriculares e de atividades, Atendimento Educacional Especializado, Ensino híbrido, novas tecnologias, aula invertida e metodologias ativas. Neuropsicologia e neurociência, oficinas de materiais pedagógicos e atividades lúdicas com materiais recicláveis, Congressos sobre Educação oferecidos por Universidades Federais, Tecnologia Assistiva, Saúde emocional durante a pandemia, resiliência, Desenho Universal para a aprendizagem, Plano de Ensino Individual (PEI) e audiodescrição, alfabetização e práticas de leitura em tempos de ensino remoto, habilidades sociais, 
http://dx.doi.org/10.5902/1984686X64174

LIBRAS, eles relataram que já estão utilizando estes conhecimentos na prática profissional e que pretendem continuar aplicando estes conhecimentos quando retornarem ao ensino presencial.

Os dados demonstraram que os professores valorizam sua formação profissional e estão em busca de conhecimentos teóricos e práticos para enfrentar esta nova realidade. Acerca da formação, diante de outras demandas neste período, Ferreira e Barbosa apontam que:

\begin{abstract}
O fechamento temporário dos prédios escolares e a decisão repentina de interrupção das aulas presenciais impossibilitou qualquer preparação, planejamento ou organização para que fossem oferecidas alternativas de extensão da rotina escolar no ambiente doméstico, seja em relação ao planejamento adequado de sequências didáticas coerentes com tal realidade, no que diz respeito à instrumentalização e à formação docente para o uso de outras ferramentas ou ainda em relação ao oferecimento de suporte técnico, de equipamentos e de infraestrutura operacional aos alunos e aos seus familiares (2020, p. 2).
\end{abstract}

Orientar professores e familiares sobre os recursos de acessibilidade e pedagógicos utilizados pelos estudantes estão dentre as atribuições do professor de AEE, de acordo com a Resolução no4/2009 (BRASIL, 2009). Então, foi perguntado se os professores do AEE têm ministrado formações para os seus colegas docentes: $76 \%$ responderam que não e $24 \%$ que sim, dentre os que responderam positivamente, as formações foram referentes às temáticas: adaptações pedagógicas, autismo, altas habilidades e estratégias de acesso ao currículo. Foram abordados, também, o atendimento remoto da sala de recursos, a preparação de material para aula on-line, importância do registro das atividades, desenho universal para a aprendizagem, maneiras lúdicas de preparar atividades que, muitas vezes, podem servir para um maior aprendizado de toda a turma, troca de experiências entre professores e outros. Relataram que normalmente estas atividades formativas ocorrem nas reuniões semanais de planejamento.

Neste período de ensino remoto, $73 \%$ dos professores disseram ter aprendido a utilizar algum software ou aplicativo que pretende incorporar às suas aulas presenciais, $25 \%$ não e $2 \%$ não responderam. Dentre os mencionados foram: Meet, editores de vídeos, powerpoint, Google forms, Google Sala de aula, Plataforma Pinterest, Zoom, Teams, noções de programação, inserção de vídeo no YouTube. Alguns professores afirmaram que já utilizavam e vão continuar utilizando.

Assim, $88 \%$ deles acreditam que suas práticas pedagógicas serão modificadas por meio das aprendizagens obtidas neste período de ensino não presencial, $11 \%$ acham que 
não e 1\% não respondeu. Os motivos revelados para crer nas mudanças foram: o contato com as famílias se intensificou, aprendizagem de novas formas de planejamento em conjunto e novos meios de compartilhar conhecimentos, maneiras de tornar os assuntos atrativos para o estudante, incluir diversos recursos facilita o desenvolvimento dos alunos, familiarização com as ferramentas digitais, pretensão de usar mais jogos e vídeos.

Dentre os que acham que não, afirmaram ter ainda que aprimorar o uso de ferramentas da Tecnologia da informação, porque os alunos não têm recursos tecnológicos, entre outros motivos. De um modo geral, comentaram que este período possibilitou algumas reflexões frente à valorização da vida, do contato e interação entre as pessoas, além de reforçar a importância da relação professor-aluno, que não deve ser substituída. "Depois, deste período, nada será como antes, portanto, não há como minha prática pedagógica ser a mesma", afirmou P49.

Este período também revelou muitas preocupações: $78 \%$ relataram preocupação com a sua saúde e de sua família, $76 \%$ com a saúde dos estudantes e de suas famílias, $75 \%$ com a volta às aulas, $46 \%$ com o desemprego, $31 \%$ revelaram preocupações políticas, $8 \%$ demonstraram preocupações em geral, desde dificuldades financeiras, desigualdades sociais que provocam miséria e mortalidade. Acerca dessa temática puderam se expressar assinalando mais de uma resposta e comentando.

A fim de amenizarem suas preocupações, os professores mencionaram buscar informações de fontes confiáveis sobre os cuidados com a saúde e medidas de prevenção, de acordo com as recomendações da OMS. Na sequência, espiritualidade e fé, prática de meditação, relaxamento e afins, bem como, exercícios físicos. Alguns participantes informaram ter reduzido o tempo que assistiam TV e ampliaram o tempo dedicado às leituras, estudos e palestras, outros às atividades culturais como: ouvir música ou assistir filmes. Em menor número, também foi comentado: cuidar das plantas, acompanhamento psicológico, diminuir o ritmo de trabalho e uso de ansiolítico. P100 mencionou: "me manter atualizada sobre as ações políticas que possam interferir direta ou indiretamente sobre mim e a minha família".

Neste período, para $50 \%$ dos participantes, a renda permaneceu a mesma, para $21 \%$ houve uma pequena redução, para $17 \%$ houve uma redução significativa na renda, $10 \%$ disseram que não houve redução, mas receia que isso aconteça, $1 \%$ relatou atraso de salário e $1 \%$ não respondeu. 
http://dx.doi.org/10.5902/1984686X64174

Os professores demonstraram tanto preocupações como possibilidades diante do contexto imposto, a maioria expressou uma atitude reflexiva e a busca de alternativa viável, pensando em oferecer o melhor ensino possível aos estudantes diante das condições dadas. Por outro lado, são pessoas que também sofreram impactos decorrentes deste período, sejam relacionados à saúde ou de ordem socioeconômica, o que deve ser considerado pelas instituições no planejamento da volta às aulas, quando for seguro para todos.

\section{Considerações finais}

Diante deste contexto inesperado da pandemia e suas consequências na vida social, dentre elas a suspensão das aulas presenciais, os professores demonstraram preocupação que os estudantes mantenham uma rotina de estudos para sua aprendizagem, bem como, demonstram sensibilidade em relação a dificuldade que muitas famílias enfrentam em relação à internet e equipamentos para as aulas on-line, buscando alternativas viáveis em cada realidade para que isso não seja mais um aspecto de exclusão, diante de tantas dificuldades já enfrentadas pelas famílias neste período.

Para a aprendizagem, é importante a intervenção do professor no momento específico que o estudante esteja realizando a atividade, ou seja, a sua atuação junto a zona de desenvolvimento do estudante, dada a mediação pedagógica que se dá nesta relação. Eis um dos desafios do ensino remoto, cujas interações se apoiam prioritariamente em expressões verbais e escritas.

Neste sentido, torna-se relevante intensificar as orientações às famílias em relação às possibilidades de mediação das atividades escolares em benefício do estudante PAEE, especificando, porém, quais as competências referentes à família, à escola e ao Estado diante da escolarização, para que não haja sobrecarga do núcleo familiar intensificando as situações de estresse já iminentes devido à pandemia.

Devido ao prolongamento da situação de isolamento físico decorrente da pandemia, recomenda-se ampliar as pesquisas com a participação do Professor do AEE, para perceber se houve alterações e perspectivas de melhoras nas condições de trabalho neste período, bem como, pesquisas com a participação de professores do ensino médio e técnico. 
http://dx.doi.org/10.5902/1984686X64174

\section{Referências}

BRASIL. Resolução no1 de 8 de junho de 2007. Estabelece normas para o funcionamento de cursos de pós-graduação lato sensu, em nível de especialização. Brasília, DF, 2007.

BRASIL. Resolução no 4 de 2 de outubro de 2009. Institui Diretrizes Operacionais para o Atendimento Educacional Especializado na Educação Básica, modalidade Educação Especial, Brasília, DF, 2009.

BRASIL. Decreto no7.611/2011. Promulgado pela Presidência da República. Dispõe sobre a educação especial, o atendimento educacional especializado e dá outras providências, Brasília, DF, 2011.

BRASIL, Parecer CNE/CP n 5 de 28 de abril de 2020. Reorganização do Calendário Escolar e da possibilidade de cômputo de atividades não presenciais para fins de cumprimento da carga horária mínima anual, em razão da Pandemia da COVID-19, Brasília, DF, 2020.

CARMO, Bruno Cleiton Macedo do. et al. Políticas públicas educacionais e formação de professores: convergências e distanciamentos na área de Educação Especial. Revista Educação Especial, v. 32, 2019. Disponível em:

https://periodicos.ufsm.br/educacaoespecial/article/view/39223

FERREIRA, Luciana Haddad; BARBOSA Andreza. Lições de quarentena: limites e possibilidades da atuação docente em época de isolamento social. Revista Práxis Educativa. v. 15, p. 1-24, Ed. UEPG, 2020. Disponível em:

https://www.revistas2.uepg.br/index.php/praxiseducativa/issue/view/694. Acesso em: 18 nov. 2020.

GADOTTI. Moacyr. Boniteza de um sonho. Ensinar e aprender com sentido. Curitiba, Positivo. 2011.

IBGE. (2018). Instituto Brasileiro de Geografia e Estatística. PNAD contínua. Pesquisa Nacional por Amostra de Domicílios Contínua. Disponível em:

https://biblioteca.ibge.gov.br/visualizacao/livros/liv101631_informativo.pdf. Acesso em 18 nov. 2020

\section{INSTITUTO RODRIGO MENDES. Protocolos sobre Educação Inclusiva durante a} pandemia da Covid-19: um sobrevoo por 23 países e organismos internacionais. 2020. Disponível em: https://institutorodrigomendes.org.br/wpcontent/uploads/2020/07/protocolos-educacao-inclusiva-durante-pandemia.pdf.Acesso em 05 fev 2021.

MENEZES, Karina Moreira. P2H: pirâmide da pedagogia hacker: [vivências do (in)possível]. Tese (Doutorado em Educação) - Universidade Federal da Bahia. Faculdade de Educação, Salvador, 2018. 
MIRANDA, Theresinha Guimarães. Articulação entre o Atendimento Educacional Especializado e o Ensino Comum: construindo sistemas educacionais inclusivos. Revista Cocar. Belém-Pará, Edição Especial, n.1, jan- jul. 2015. p. 81-100. Disponível em: https://periodicos.uepa.br/index.php/cocar/article/view/614. Acesso em: 18 de jul 2020.

OLIVEIRA, Ana Augusta. Sampaio de; LEITE, Lúcia. Pereira. Construção de um sistema educacional inclusivo. Ensaio: Avaliação e Políticas Públicas em Educação, v. 15, 2007, p. 511-524. Disponível em: https://www.scielo.br/pdf/ensaio/v15n57/a04v5715.pdf. Acesso em: 06 fev.2021.

PAGAIME, Adriana et al. Inclusão escolar em tempos de pandemia. Fundação Carlos Chagas, 2020. Disponível em: https://www.fcc.org.br/inclusao-escolar-em-tempos-depandemia/index.php. Acesso em: 18 nov. 2020.

QUEIROZ, Fernanda Matrigani Mercado Gutierres de. Tecnologia Assistiva e perfil funcional dos alunos com deficiência física nas salas de recursos multifuncionais. Dissertação (Mestrado em Educação). Universidade Estadual Paulista "JULIO DE MESQUITA FILHO." Campus de Marília, 2015.

STAINBACK, Susan.; STAINBACK, William. Inclusão: um guia para educadores. Artmed, Ed. Porto Alegre: trad. Magda França Lopes, 1999.

TELLES, Priscila Moreira Corrêa (Org.) Guia Orientativo: Elaboração de materiais educativos acessíveis. NAPNE/ IFSP. 2020. Disponível em:

https://www.ifsp.edu.br/ultimas-noticias/1660-napne-ifsp-lanca-guia-com-orientacoes-paraelaboracao-de-materiais-acessiveis. Acesso em 18 nov. 2020.

VIEIRA, Sonia. Como elaborar questionários. Ed. Atlas. São Paulo, 2009.

\section{Notas}

${ }^{1}$ Identificados neste trabalho de P1 até P100. International (CC BY-NC 4.0) 